\title{
Development and Psychometric Properties of an Instrument for the Assessment of Assertiveness in Sexual Relations
}

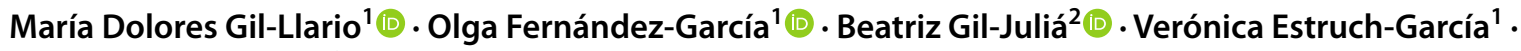 \\ Rafael Ballester-Arnal ${ }^{3}$
}

Accepted: 26 July 2021 / Published online: 3 August 2021

(c) The Author(s) 2021

\begin{abstract}
Introduction The potential consequences of being assertive or non-assertive for people's sexual health and sexual well-being highlight the importance of assessing sexual assertiveness (SA). The currently available measures have limitations because they do not take recent social changes into account, they are designed to only assess women, and/or they ignore several components of SA. This study tests the psychometric properties of the Assertiveness in Sexual Relations Questionnaire (ASRQ). Methods Thus, 2370 participants (aged 18-69 years) of Spain completed the ASRQ, along with other scales that assesses related dimensions (e.g., family values in relation to sexual assertiveness, sexual esteem). Data were collected during 2020. Results Exploratory factor analysis yielded a four-factor structure: Assertive behavior as initiative, sub-assertive behavior, overly assertive behavior as initiative, and assertive behavior as a response, which was verified by confirmatory factor analysis (CFA). A multigroup CFA was also conducted in men and women, confirming the adequacy of this four-factor structure across genders. The reliability of the factors ranged from 0.72 to 0.87 . Similarly, correlations with related scales were mostly significant and in the expected direction.

Conclusions The psychometric results obtained support the use of the ASRQ as a reliable and valid measure to assess sexual assertiveness in both men and women.

Policy Implications

The availability of an instrument to assess sexual assertiveness, whose psychometric properties have been satisfactorily tested, benefits society by contributing to the improvement of the sexual health of the population, allowing for more effective interventions and the early detection of skills that contribute to the establishment of risky sexual interactions.
\end{abstract}

Keywords Assertive behaviors · Assertiveness in Sexual Relations Questionnaire (ASRQ) - Overly assertive behaviors · Psychometric properties $\cdot$ Sub-assertive behaviors

\section{Introduction}

Sexuality can be understood as a multidimensional component of the human being that arises from a spectrum of different physical, social, and emotional experiences that

Olga Fernández-García

olga.fernandez-garcia@uv.es

María Dolores Gil-Llario

dolores.gil@uv.es

Beatriz Gil-Juliá

beatriz.gil@uv.es

Verónica Estruch-García

veronicaestruch11@gmail.com

Rafael Ballester-Arnal

rballest@uji.es occur as normative aspects of healthy sexual development (Teitelman et al., 2009). Specifically in the expression of sexuality, two dimensions can be distinguished, one where only the protagonist is involved, that is, autoeroticism, and one where two or more people participate. In

1 Department of Developmental and Educational Psychology, University of Valencia, Valencia, Spain

2 Department of Personality, Assessment, and Psychological Treatments, University of Valencia, Valencia, Spain

3 Department of Basic and Clinical Psychology and Psychobiology, Jaume I University, Castello de la Plana, Spain 
the case of autoeroticism, the practitioner can rely more or less on pornography, either online or offline, or simply draw on his/her fantasies. In any case, the individual has absolute control over the practice and can start, prolong, or stop it at will (Paredes Robalino et al., 2020). However, in the case of sexuality "in a relationship," given that other people are involved, the protagonist does not have complete control and may sometimes be pressured, more or less consciously, to perform the sexual practice or, in contrast, apply pressure or insist that the other person perform it (Fernández-Fuertes et al., 2020). The pressure a person can exert or receive from another person to engage in a certain sexual practice might respond to personality characteristics. However, even if this is true, there is no doubt that the context where individuals are socialized makes them more likely to develop a more or less passive role depending on the prevailing socio-cultural values (Wiederman, 2015).

Traditional cultures have given men the responsibility of taking the initiative to start a relationship, encouraging them to develop skills to convince or win the favor of women, whereas women have been educated in a more passive role, which makes it more difficult for them to make their will prevail, even to the point of not being fully aware of it (Zhang \& Yip, 2018). In this regard, research shows a pattern where men tend to take the sexual initiative (Vannier \& O'Sullivan, 2011; Sánchez et al., 2012) about twice as often as women (Grøntvedt et al., 2015; Impett \& Peplau, 2003). However, in recent decades, this trend has been changing, and women are gradually taking a more active role in some aspects of their sexual relationships, for example, by taking the initiative to start dating. Despite this, it is not known whether this incipient tendency to take control also applies to sexual practices, including the ability to initiate a certain sexual contact or stop the sexual activity when it reaches an undesired point. Some empirical studies have reported automatic associations between sexuality and power that reinforce gender stereotyped behavior in sexual contexts, which would explain why individuals in the most powerful positions in society (men) are more assertive and confident in their sexual relationships (Lammers \& Stoker, 2019; Sanchez et al., 2012).

In this framework, the concept of assertiveness is particularly relevant. Assertiveness is defined as an individual's ability to communicate his or her views, opinions, beliefs, or feelings to another person in an effective manner and without infringing or denying the other person's rights (Alberti \& Emmons, 1978; Kelly, 2000). Assertiveness is not a categorical characteristic. Instead, it extends along a continuum from excessive passivity, or not being able to assert one's needs and rights and set limits, to excessive hostility, or disregarding the needs and rights of others. Likewise, in both assertive and aggressive behaviors, the individual opposes the intentions of the other, but unlike aggressive behavior, the assertive person communicates his/her position and gives information to others about how he/she wants to be treated in a firm and convincing, but never hostile, way (Ballester-Arnal \& Gil-Juliá 2012; Speed et al., 2018). However, assertiveness is situation-specific because, as Zamboni et al. (2000) point out, subjects who are assertive in their day-to-day lives may not be assertive in the sexual domain, and so it is important to assess this trait in specific sexual contexts (Livingston et al., 2007). Thus, sexual assertiveness (SA) can be understood as a social skill that allows one to openly communicate sexual thoughts, feelings, preferences, needs, or opinions to others, based on the human right that assumes that people should be able to choose their own sexual existence and activity (Erchull \& Liss, 2014; Koolaee et al., 2014; Loshek $\&$ Terrell, 2015; Santos-Iglesias et al., 2014).

Sexually assertive people report greater sexual desire, feel more satisfied in their sexual and marital relationships (Carrobles et al., 2011), and have better sexual functioning (Brassard et al., 2015) because they are not only able to communicate their sexual preferences, but they also have the ability to experience sexual pleasure without fear of rejection (Ménard \& Offman, 2009). Several studies have also found a positive and significant relationship between sexual self-esteem and SA, indicating that those who have a positive view of their sexual life and are confident about their ability to experience satisfying sexuality are more capable of making decisions in their sexual relationships (Brassard et al., 2015; Torres-Obregon et al., 2017). In addition, sexual self-esteem also appears to contribute to good interpersonal functioning and the development of a healthy sex life (Giordano \& Rush, 2010), thus decreasing sexual difficulties and improving sexual satisfaction.

However, not only has SA been linked to sexual wellbeing from a more positivist perspective that focuses on enjoyment, but a lack of SA can also have negative consequences if the ability to negotiate during sexual practices is impaired by default or by excess. One of its negative consequences is related to sexual violence. A 2017 meta-analysis concluded that approximately 1 in 10 adolescents or young adults reported experiencing sexual violence (Wincentak et al., 2017). In Spain, a study focusing on adolescent relationships found that around $57 \%$ of the women and $58 \%$ of the men surveyed had experienced some form of sexual violence at the hands of their partners, figures comparable to the percentage of women and men who admitted to committing these behaviors: $44 \%$ and $61 \%$, respectively (FernándezFuertes et al., 2011). Recent research has identified SA as a protective factor against sexual violence and re-victimization. Moreover, in a reciprocal manner, people with a history of sexual victimization have lower SA and vice versa (Kelley et al., 2016; Krahé \& Berger, 2017; Livingston et al., 2007). At the same time, a higher incidence of risky sexual behavior, 
such as non-use of condoms or non-consensual condom removal during intercourse, has also been detected ("stealthing") (Davis, 2019; Davis et al., 2014; Kuyper et al., 2013; Stappenbeck et al., 2019), thus increasing the likelihood of STIs and unwanted pregnancies (Williams et al., 2013).

Due to the various implications of SA in different aspects of life in general and in sexual health in particular, it becomes a key skill that needs to be taken into account in both clinical and community settings and accurately assessed. In the scientific literature reviewed, several instruments were found that assess SA. Although they are wellintentioned measures, they are limited in different ways. Among the most widely used instruments, the one designed by Morokoff et al. (1997) consists of a total of 18 items that assess three components of SA (initiation of desired sexual activities, rejection of unwanted sexual activities, and pregnancy prevention-STD), and the Hurlbert Index of Sexual Assertiveness (HISA) (Hurlbert, 1991) contains a total of 25 Likert-type items that assess communication with the partner and the ability to initiate desired sexual activities or reject unwanted sexual activities. Both scales include specific components of SA, but they do not address assertiveness in communicating sexual preferences and sexual satisfaction, among other aspects. Furthermore, their main drawback is that, because they are older instruments, they present a perspective that is not in line with recent social changes and the new conceptualization of gender roles. On the other hand, the Assertive Sexual Communication Scale (ASCS) (Quina et al., 2000) more specifically assesses communication about satisfaction, sexual desires, and one's sexual history, but it does not address the initiation of desired sex or the rejection of unwanted sex. More recently, Loshek and Terrell (2015) designed an 18-item scale intended to provide a comprehensive assessment of SA, but they did not include the important topic of negotiating contraception use. All these instruments were designed to focus solely on assessing the sexuality of female participants, despite evidence that this is likely to be an important construct for men as well (Loshek \& Terrell, 2015). An additional limitation is that all these scales focus on the assessment of SA in the context of stable affective partnerships, without taking into account the broad casuistry of coincidental sexual interactions, e.g., under the influence of alcohol or other drugs. This is a serious drawback if we consider that casual or occasional sexual relations are becoming more and more frequent in our society, and that they have different characteristics because they are encounters where psychophysiological impulses and passion take precedence over intimacy and commitment (Soriano-Ayala \& García-Serrán, 2019). In this sense, the Brief Condom Use Self-Efficacy Scale (GilLlario, et al., 2019) overcomes the latter limitations and was validated in the Spanish context. However, it only addresses the ability to make condom use prevail in sexual relations.
It is a scale that fundamentally analyzes self-efficacy in the use of this contraceptive method, and neither does it address the person's ability to accept or reject any sexual interaction regardless of the specific moment, nor does it take into account those situations in which undue pressure is exerted on the other person.

Given the transcendence of this construct in the sexual health of men and women and the limitations of the available scales to assess AS, the current study sought to create a new test that could (a) be used to assess sexual assertiveness in the Spanish context, (b) be equally applicable to both men and women, and (c) take into account the different types of current sexual relationships and their special features, considering, at the same time, the wide variety of sexual practices that can be carried out. To achieve these aims, we designed a new measure to assess sexual assertiveness: the Assertiveness in Sexual Relations Questionnaire (ASRQ). In this study, we describe some of its methodological and psychometric properties.

\section{Methods}

\section{Participants}

The study sample included 2370 participants with an age range between 18 and 69 years $(M=24.28 ; \mathrm{SD}=8.04)$, who lived in the Comunitat Valenciana (Spain). The distribution of the participants by gender was $62.6 \%$ women, $36.2 \%$ men, and $1.2 \%$ non-binary. The majority of the participants identified themselves as heterosexual $(70.4 \%)$, followed by $20.2 \%$ who identified as bisexual, $8.8 \%$ as homosexual, and $0.6 \%$ as other (asexual, pansexual, etc.). In addition, $56.5 \%$ of the participants claimed to have a steady partner, whereas $43.5 \%$ did not.

The initial group of 2370 participants was randomly divided into two subsamples. The first subsample, which was used to perform the Exploratory Factor Analysis (EFA), was made up of 1200 subjects ( $63.1 \%$ women, $35.7 \%$ men, and $1.2 \%$ non-binary), with a mean age of 24.34 years ( $\mathrm{SD}=$ 8.14). The second subgroup, which was used to perform the Confirmatory Factor Analysis (CFA), was made up of 1170 subjects (62.2\% women, $36.6 \%$ men, and $1.2 \%$ non-binary), with a mean age of 24.21 years $(\mathrm{SD}=7.93)$. There were no statistically significant differences between the subsamples in gender $\left(\chi^{2}=0.615, p=0.538\right)$ or age $(t=-0.381, p=0.703)$.

\section{Measures}

\section{Assertiveness in Sexual Relations Questionnaire}

This instrument was elaborated by drawing on the scientific literature on SA and the expertise of a group of human sexuality researchers. The initial measure (ASRQ) is a 40 -item 
self-reported instrument designed to determine the person's skills in communicating his/her sexual thoughts and feelings, without offending or hurting the other person or feeling bad about him/herself. It includes items that refer to assertive communication in diverse sexual scenarios: during flirtation (e.g., "When I like a person, I flirt insistently -I dance very close, I do not separate myself from that person, etc."); when exchanging kisses, embraces, and fondling (e.g., "When I want my partner to touch or hug me, I ask him/her to" and "If my partner pushes me, I give in and kiss him/ her, even if I've already said no"); to initiate different sexual practices (e.g., "I insist on engaging in sexual practices that I know my partner doesn't like, because I do"); while engaging in sexual practices that you do not like (e.g., "If my partner asks me to engage in a sexual practice that I don't like (mutual masturbation, oral sex, anal sex, introduction of sex toys...), I refuse"); in the context of the use of condoms or latex barriers during sexual intercourse (e.g., "If I want to use a condom or latex barrier and my partner doesn't want to, I refuse to have sex"); and in the context of having consumed alcohol or drugs (e.g., "When I consume alcohol or drugs, I demand to have sex with my partner"). Likewise, we can differentiate items with a more passive nuance, purely assertive ones, or those reflecting aggressiveness. At the same time, some of them focus on initiating requests, whereas others focus on responding to requests. Participants rate each item on a 4-point Likert-type scale ranging from 0 (never) to 3 (always).

\section{Sexual Esteem Subscale of the Multidimensional Sexuality Questionnaire}

The MSQ (Snell et al., 1993) is a validated self-reported instrument that measures different psychological tendencies associated with sex, and it contains 60 items distributed in 12 subscales. In this study, participants only completed the five-item Sexual Esteem subscale, which measures the generalized tendency to positively evaluate one's capacity to relate sexually to another person. Each item asks respondents to rate their response on a Likert-type scale from 1 (not at all characteristic of me) to 5 (very characteristic of me). The internal consistency of this MSQ subscale in the current study, using Cronbach's alpha, was .86.

\section{Parental Values Transmitted in Relation to Sexual Assertiveness (PaVa-SA)}

This is a five-item self-administered instrument developed by Estruch-García and Gil-Llario (2020) that assesses the participants' perception of the values their parents transmitted to them about assertive communication with their partner. The items included in this tool are "I have to clearly tell my partner what I like to do"; "I have to do what my partner wants in order to make him/her happy"; "If there are things I feel like doing, I will make my partner do them, even if he/she doesn't want to"; "If I don't like to use a condom, I will force my partner to do without it"; and "If I want to use a condom and my partner does not, I can refuse to have sex with him/her", and participants are asked to respond to these questions thinking about the values transmitted to them by their parents. Responses are given on a Likert-type scale with five options ranging from 1 (strongly disagree) to 5 (strongly agree). Higher scores indicate that the respondent perceives that his/her parents have instilled more assertive interpersonal communication skills in him/her, given that the second, third, and fourth items are reverse scored.

\section{Procedure}

For the construction of the ASRQ, we followed the Delphi method (Mokkink et al., 2010). First, the construct under study was precisely defined on the basis of a thorough literature review, and previous scales and tests in the literature on sexual assertiveness were analyzed, examining their content (constructs and areas assessed), format (response format, number of items, etc.), structure (factorial solutions), and procedures followed for their validation (sample characteristics, etc.). This review was carried out by the members of the research team in charge of developing the ASRQ.

Based on this search, we proposed a preliminary set of items that we then shared with an advisory board composed of five researchers with expertise in human sexuality and experience in the development and validation of assessment instruments. The aim was to assess the degree of relevance of the items by indicating the relevance of each item in the construct, thus increasing the content validity of the ASRQ by revising the proposed items and proposing new ones. As a result of this analysis, four items that were not found to assess the construct under study were eliminated, eight items were reformulated to clarify their meaning and improve their comprehension, and seven items were added that were more related to the more hostile extreme of assertive communication. The resulting document was again reviewed by the board of experts, who ratified its structure.

After this last step, the instrument consisted of 40 Likerttype scale items with four response options, and this provisional version of the ASRQ was administered to 20 people aged 18-57 to determine whether the items were correctly understood. This step allowed new revisions of the items, improving the wording of six of them, clarifying them, and adapting them to more inclusive language. After several improvements were made based on the participants' suggestions, the final version was ready.

Assessment instruments were administered through the LimeSurvey online platform, which allowed us to enhance adherence to ethical principles during the evaluation 
(informed consent is required to access the battery of questionnaires, the IP address of the device from which the user accesses is not recorded, etc.). The link to the platform was widely shared through various channels, and non-probability sampling using the snowball technique was also performed. First, it was published on the official social networks of the research team (website, Facebook, Twitter, and Instagram of the research team), and second, it was distributed among university students in various degree programs at several universities in the Comunitat Valenciana, urging them to share it on their own social networks and with their acquaintances. The specific objective of the investigation was not mentioned to avoid biasing the sampling process. They were only told to express the extent to which they identified with different statements related to their sexuality. Data derived from the online platform were processed to avoid duplicate responses, and only those participants who had correctly completed the scale were included in the study.

\section{Data Analysis}

First, we performed descriptive analyses of sociodemographic data using the SPSS statistical package (version 26.0). To compare participants' characteristics in the two groups (EFA and CFA), we performed $T$ tests (continuous variables) and $\chi^{2}$ tests (categorical variables).

To determine the factorial structure of the ASRQ, we first performed an EFA, considering only the participants in the first subsample. As a preliminary step to determine the properties of the correlation matrix of the items, the Kaiser-Meyer-Olkin test and the Bartlett sphericity test were used. The FACTOR software (version 9.2) was used to perform the EFA (LorenzoSeva \& Ferrando, 2013). The main advantage of FACTOR compared to other statistical software is the possibility of performing the EFA on the basis of the tetrachoric/polychoric correlation matrix; this option is preferable when modeling Likert data (as in the case of the ASRQ; Ferrando \& LorenzoSeva, 2017). We used parallel analysis to determine the number of factors to extract (Timmerman \& Lorenzo-Seva, 2011), and they were extracted through robust diagonally weighted least squares (DWLS), applying orthogonal rotation (normalized varimax).

Subsequently, a CFA was performed with the participants in the second subgroup. The fit of four-factor models was compared, and a multigroup CFA was performed to test the hypothesis of measurement invariance (configural, metric, and scalar) according to gender. The software used to perform these analyses was IBM SPSS Amos 24. The goodness of fit of the different factorial models was analyzed using the following indices: chi-square $\left(\chi^{2}\right)$, normed chi-square $\left(\chi^{2} / \mathrm{df}\right)$, general model significance $(p)$, root mean square error of approximation (RMSEA), and comparative and incremental fit indices (CFI and IFI). An appropriate fit was considered when $\chi^{2}$ was not significant $(p>.05), \chi^{2} / \mathrm{df}$ was between 1 and 2, CFI and IFI were $\geq 0.95$, and RMSEA was $\leq 0.05$ (Bagozzi \& Yi, 2011). According to less restrictive criteria, values between 2 and 3 for $\chi^{2} / \mathrm{df}, \geq 0.90$ for CFI and IFI, and $\leq 0.08$ for RMSEA could also be considered acceptable (Hooper et al., 2008).

Finally, the general mean scores for the items and subscales of the ASRQ were explored. In addition, different reliability indices were calculated, in particular, the ordinal Cronbach's alpha, the ordinal omega coefficient, and each item's correlation with its factor. Convergent validity was also explored by correlating (Pearson's $r$ ) the ASRQ subscale scores with related measures.

\section{Results}

\section{EFA of the ASRQ}

To verify the applicability of the EFA to the ASRQ, we calculated the Kaiser-Meyer-Olkin index $(\mathrm{KMO}=0.84)$ and Bartlett's test for sphericity $\left[\chi^{2}(351)=6328.50, p<\right.$ $.001]$, obtaining results that indicated that the questionnaire admits a factorial solution. Then, to determine the number of factors to be retained, we performed a parallel analysis of the polychoric correlation matrix (Garrido et al., 2013), using the diagonally weighted least squares (DWLS) estimator because it is the most suitable for big sample sizes and categorical variables (DiStefano \& Morgan, 2014). The results suggested either a three-factor or a four-factor structure. However, the four-factor structure showed a better fit to the data and to the theoretical model followed by the authors during the development of the instrument (Table 1).

\section{CFA of the ASRQ}

To verify the structure, a confirmatory factor analysis (CFA) was performed using the maximum likelihood method. This method allows us to obtain statistics that correct the normality violation, and it is recommended when analyzing categorical variables (Finney \& DiStefano, 2013).

The first model tested (M1) exactly replicated the factor structure derived from the EFA, with correlated first-order factors, deleting the items with factor saturations below .40 and the items that presented cross correlations. Hence, we decided to exclude items $3,26,34,36$, and 38 because they showed factor saturations below .40, and items 5, 8, 10, 14, $15,21,27$, and 37 because they presented cross correlations. The fit indexes obtained were slightly below the cutoff values $(\mathrm{CFI}=.862$, IFI $=.863)$, although the RMSEA was good (0.048).

For this reason, a second model (M2) was tested, imposing a series of constrictions to improve the model 
Table 1 ASRQ factorial loadings

Items

Factorial loadings

Factor 1 Factor 2 Factor 3 Factor 4

1. I tell my partner what parts of my body I like to have touched. ${ }^{\mathrm{a}}$

.48

2. I am ashamed to ask my partner to engage in the sexual practices that I would like to do. ${ }^{a}$

3. I take my partner's hand and put it on the parts where I like to be touched, even if my partner doesn't want to.

4. When I feel like it, I ask my partner to initiate sex. ${ }^{a}$

5. I agree to engage in sexual practices that I don't feel like doing because I don't want my partner to feel bad.

6. I am ashamed to ask my partner to touch me on the parts that I like. ${ }^{\mathrm{a}}$

7. If my partner insists, I have sex without using a condom or latex barrier, even if I don't want to. ${ }^{\text {a }}$

8. I tell my partner where I don't like to be touched.

9. When I want to have sex, I wait for my partner to ask me to initiate sex. ${ }^{\mathrm{a}}$

10. I remove my partner's hand from the parts of my body where I have told him I do not like to be touched.

11. When I want my partner to touch or hug me, I demand it. ${ }^{a}$

12. I am ashamed to tell my partner that I do not want to engage in a sexual practice that he/she asks me for. $^{\mathrm{a}}$

13. When I want my partner to touch or hug me, I ask him/her to. ${ }^{\text {a }}$

14. If my partner pushes me, I give in and kiss him/her, even if I've already said no.

15. I have sex if the other person wants to, even when I don't feel like it.

16. I refuse to let my partner caress my body if I don't want to, even when he/she insists. ${ }^{a}$

17. I insist on engaging in sexual practices that I know my partner doesn't like, because I do. ${ }^{a}$

18. I take my partner's hand and put it on the parts that I like him to touch, without bothering him. ${ }^{\text {a }}$

19. I refuse to have sex if I don't feel like it, even if my partner insists. ${ }^{a}$

20. I pressure my partner to initiate sex when I feel like it. ${ }^{a}$

21. When my partner has consumed alcohol or drugs and asks me to have sex, I agree in order to avoid problems.

22. If my partner asks me to engage in a sexual practice that hurts me (anal sex) or makes me feel humiliated, I refuse to do it. ${ }^{\text {a }}$

23. When I consume alcohol or drugs, I demand to have sex with my partner. ${ }^{\mathrm{a}}$

24. If I want to use a condom or latex barrier and my partner doesn't want to, I refuse to have sex. ${ }^{\text {a }}$

25. When I want us to engage in a sexual practice, I pressure my partner if he/she says that he/he doesn't want to. ${ }^{\mathrm{a}}$

26. When my partner has consumed alcohol or drugs and asks me to have sex, I tell him/her that in that state I don't want to.

27. If my partner asks me to send him/her photos without clothes, I do it to avoid problems.

28. If my partner asks me to engage in a sexual practice that I don't like (mutual masturbation, oral sex, anal sex, introduction of sex toys...), I refuse. ${ }^{\mathrm{a}}$

29. If I want to use a condom or latex barrier, I demand that my partner put it on. ${ }^{a}$

30. When we are doing a sexual practice and I want to stop, even if I like it at first, I am able to tell the other person. ${ }^{\mathrm{a}}$

31. I have pressured someone else to have sex, even though I wasn't sure he/she wanted to. ${ }^{\text {a }}$

42

.79

49

.37

66

.41

.54

.37

$-.41$

.61

.77

.62

35. If the person I'm interested in tells me that he/she doesn't want to do anything with me, I keep insisting until he agrees. ${ }^{a}$

36. If all my friends have already had sex with their partners, I think I should too. 
Table 1 (continued)

\begin{tabular}{|c|c|c|c|c|}
\hline \multirow[b]{2}{*}{ Items } & \multicolumn{4}{|c|}{ Factorial loadings } \\
\hline & Factor 1 & Factor 2 & Factor 3 & Factor 4 \\
\hline $\begin{array}{l}\text { 37. I'm at a party and a quite attractive person asks me to go to a more intimate place together. Although } \\
\text { I don't feel like it, I say yes. }\end{array}$ & & .38 & .47 & -.33 \\
\hline 38. The first time I had sex I did it because all my friends had already done it. & & .36 & .32 & \\
\hline 39. When someone insistently tries to seduce me, I end up giving in. & & & .45 & \\
\hline $\begin{array}{l}\text { 40. I make the other person see that I am not interested in doing anything with him, distancing myself } \\
\text { with looks or other strategies. }\end{array}$ & & & & .41 \\
\hline Eigenvalue & 9.90 & 4.34 & 2.81 & 1.99 \\
\hline
\end{tabular}

${ }^{\mathrm{a}}$ Items that are part of the final version of the ASRQ

fit. Following the modification index (MI) and expected parameter change (EPC) indications, item 40 ("I make the other person see that I am not interested in doing anything with him, distancing myself with looks or other strategies") was eliminated because it showed the lowest saturation in M1; and items 32 ("If all my friends had a partner and I did not, I would have sexual contact with the first person I could, even if I did not like him/her") and 39 ("When someone insistently tries to seduce me, I end up giving in") from factor 3 were removed because they presented some theoretical inconsistencies with the rest of the items. Moreover, following the MI, a constriction was imposed to improve the model fit. Specifically, the residual covariances of item 24 were correlated with those of item 29 because both items have similar wording (Long, 1983; item 24: "If I want to use a condom or latex barrier and my partner doesn't want to, I refuse to have sex"; item 29: "If I want to use a condom or latex barrier, I demand that my partner put it on").

As Table 2 shows, the significance value of the chi-square statistic is significant $(p=.001)$. Nevertheless, this statistic is highly conditioned by sample size (Markland, 2007), and so it may be more appropriate to use other indices considered less sensitive to sample size. In this regard, the value corresponding to the normed chi-square $\left(\chi^{2} / \mathrm{df}\right)$ was 2.95 , with acceptable values being less than 3 and perfect values lying between 1 and 2. The RMSEA was below the value of .05 required by the strictest criterion for considering a model parsimonious. Finally, the CFI and IFI reached a value of 0.914 , which is beyond the cutoff point established for an acceptable fit to the model. The resulting model can be seen in Fig. 1.

The first factor is composed of four items (items 1, 4, 13, and 18). This factor was called "Assertive behavior as initiative" because it groups together items that reflect the person's ability to make requests assertively and express his/her own wishes without hurting the other person (e.g., "When I want my partner to touch or hug me, I ask him/her to"). The total score on this factor, obtained by adding the scores on each item, can range from 0 to 12 . A higher score on this dimension reports a greater ability to make requests and express wishes in an assertive way when engaging in sexual practices.

The four items that make up the second factor (items 2 , 6,9 , and 12) collect information about the tendency to make passive requests (e.g., "I am ashamed to ask my partner to touch me on the parts that I like") and responses (e.g., "I am ashamed to tell my partner that I do not want to engage in a sexual practice that he/she asks me for") regarding the performance of sexual practices, highlighting the lack of initiative and withdrawal due to shame. This factor was called "Sub-assertive behavior." The total score on this factor,
Table 2 Goodness-of-fit indexes for the CFA and the multigroup CFA

\begin{tabular}{lrllllll}
\hline & \multicolumn{1}{c}{$\chi^{2}$} & df & \multicolumn{1}{c}{$p$} & $\chi^{2} / \mathrm{df}$ & CFI & IFI & RMSEA (90\%) \\
\hline Tested models & & & & & & & \\
Model 1 & 1178.889 & 318 & .001 & 3.707 & .862 & .863 & $.048(.045-.051)$ \\
Model 2 & 724.547 & 245 & .001 & 2.957 & .914 & .914 & $.041(.037-.044)$ \\
Multigroup CFA for gender & & & & & & & \\
Configural invariance & 972.572 & 490 & .001 & 1.985 & .907 & .908 & $.029(.027-.032)$ \\
Metric invariance & 1024.355 & 510 & .001 & 2.009 & .901 & .901 & $.030(.027-.032)$ \\
Scalar invariance & 1030.881 & 510 & .001 & 2.021 & .899 & .900 & $.030(.027-.032)$ \\
\hline
\end{tabular}

$\chi^{2}$, chi-square; $d f$, degrees of freedom; $p$, general model significance; $\chi^{2} / d f$, normed chi-square; $C F I$, comparative fit index; IFI, incremental fit index; RMSEA, root mean square error of approximation 


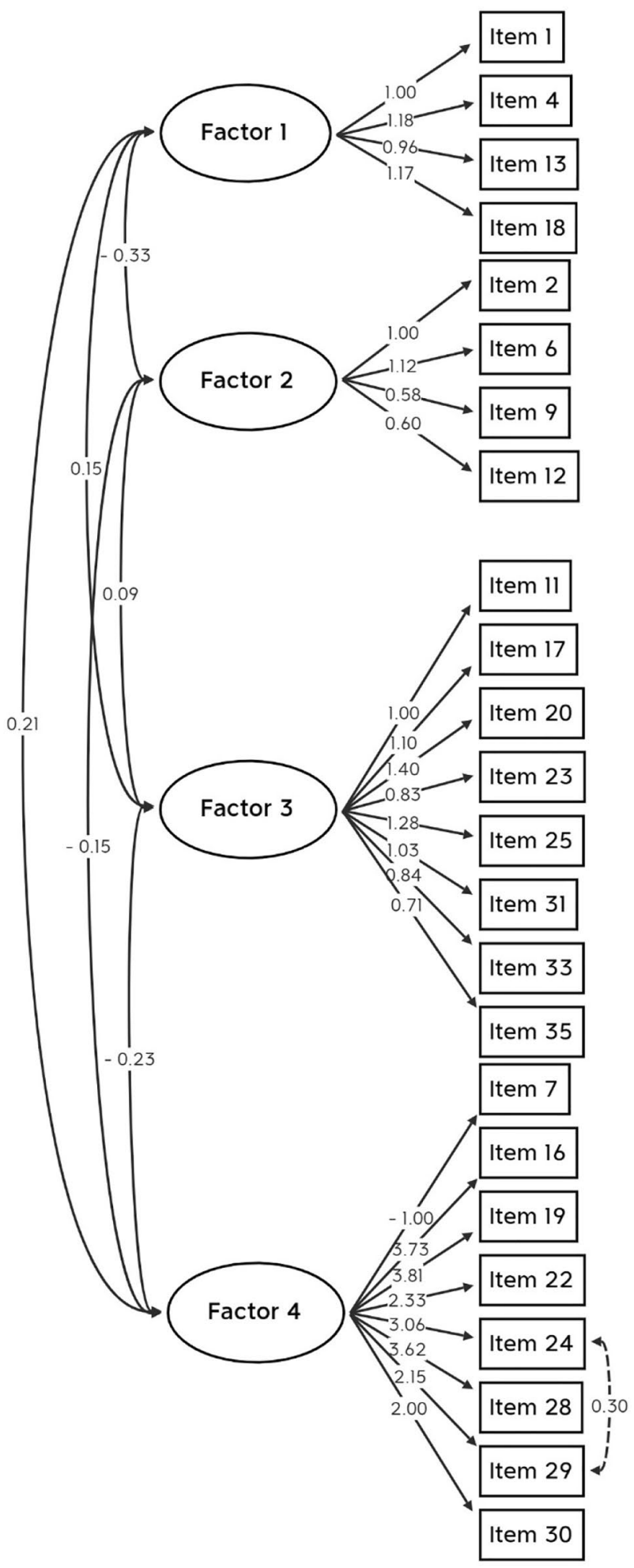

Fig. 1 CFA for the ASRQ

obtained by adding the scores on each item, can range from 0 to 12 . A higher score in this factor reports more passive requests and responses during sexual interactions.
The third factor groups eight items (items 11, 17, 20, 23, $25,31,33$, and 35) that reflect the tendency to make hostile requests (e.g., "When I want my partner to touch or hug me, I demand it") and impose one's wishes on the partner (e.g., "I insist on engaging in sexual practices that I know my partner doesn't like, because I do"), highlighting the pressure applied to achieve their fulfilment. Therefore, this factor was called "Overly assertive behavior as initiative." The total score on this factor, obtained by adding the scores on each item, can range from 0 to 24, and reports more hostile communication during sexual interactions as the score on this factor increases.

The fourth and final factor integrates the remaining eight items (items 7, 16, 19, 22, 24, 28, 29, and 30), which evaluate the person's ability to respond assertively to requests of a sexual nature (e.g., "I refuse to have sex if I don't feel like it, even if my partner insists"), highlighting the ability to reject or refuse to do what you do not want to do. This factor is called "Assertive behavior as a response." The total score on this factor, obtained by adding the scores on each item, can range from 0 to 24 , with a higher score indicating a greater ability to respond assertively to sexual requests.

To confirm whether the factor structure was applicable to men and women, we performed three multigroup CFAs according to gender. In the first, the hypothesis of factor structure invariance (structural invariance) was tested, whereas in the second, the invariance of the factor loadings (metric invariance) was analyzed. In addition, we tested the hypothesis of the intercepts' invariance (scalar invariance). As Table 2 shows, the chi-square tests are significant. Regarding the RMSEA values for the evaluation of the three types of invariance, all the models analyzed present values below the cutoff point (0.05) established for excellent fit (Bagozzi \& Yi, 2011). In addition, the CFI statistic is above the cutoff point $(0.90)$ established for acceptability (Hooper et al., 2008) of the configural and metric invariance models, and the IFI statistic is equal to or greater than the cutoff point $(0.90)$ for the three models. The only value that would be below the accepted limit (0.90), but very close to it, is the CFI statistic for the scalar invariance model. Nevertheless, the IFI statistic for the scalar invariance model is equal to the cutoff point $(0.90)$, and so we can conclude that the factor structure of the ASRQ is equivalent in men and women. Furthermore, factor loadings and item intercepts did not vary significantly based on gender.

\section{Descriptive Data and Reliability of the ASRQ}

Mean scores on the ASRQ items and factors are reported in Table 3 for the total sample. As the table shows, the items with the highest mean scores were items 7 ("If my partner insists, I have sex without using a condom or latex barrier, even if I don't want to"; $\mathrm{M}=2.74 ; \mathrm{SD}=.62$; inverse item) and 22 ("If my partner asks me to engage in a sexual practice that hurts me (anal sex) or makes me feel humiliated, 
I refuse to do it"; $M=2.50 ; \mathrm{SD}=.99$ ), whereas the lowest mean score was for item 23 ("When I consume alcohol or drugs, I demand to have sex with my partner"; $M=.17$; SD $=.47$ ) and 35 ("If the person I'm interested in tells me that he/she doesn't want to do anything with me, I keep insisting until he agrees"; $\mathrm{M}=.17 ; \mathrm{SD}=.46$ ). At the same time, regarding the four factors, and taking into account that their ranges of scores are different, the highest mean score is found for factor 4 (range $=0-24 ; M=18.04 ; \mathrm{SD}=4.86$ ), whereas the second (range $=0-12 ; M=2.25 ; \mathrm{SD}=2.08$ ) and third (range $=0-24 ; M=2.18 ; \mathrm{SD}=2.67$ ) factors show the lowest mean scores.
In addition, the $T$-test showed statistically significant gender differences in the scores on the four ASRQ factors. Women scored higher than men on factors 1 and 4 , whereas men obtained higher scores than women on factors 2 and 3 .

Regarding internal consistency, ordinal Cronbach's $\alpha$ and $\Omega$ for the ASRQ factors exceed the criterion of .70 (Hunsley \& Mash, 2008) for considering the reliability of a scale appropriate. Specifically, reliability evaluated through both indices reaches very similar values, ranging from .72 to .87 . Internal consistency was also supported by item-scale correlations (between .43 and .75).

Table 3 Descriptive statistics, $T$-test for gender, and reliability indexes for items and factors on the ASRQ

\begin{tabular}{|c|c|c|c|c|c|c|c|c|}
\hline & \multicolumn{2}{|c|}{$\begin{array}{l}\text { Normative data of total } \\
\text { sample } \\
(n=2.370)\end{array}$} & \multicolumn{3}{|c|}{$T$-test regarding gender } & \multicolumn{3}{|c|}{ Reliability indexes } \\
\hline & Range & $\mathrm{M}(\mathrm{SD})$ & $\begin{array}{l}\text { Women } \\
M(\mathrm{SD})\end{array}$ & $\begin{array}{l}\text { Men } \\
M(\mathrm{SD})\end{array}$ & $F_{(1,2.370)}$ & $\alpha(\mathrm{CI})$ & $\Omega(\mathrm{CI})$ & $\mathrm{I}-\mathrm{F} r$ \\
\hline ASRQ factor 1 & $0-12$ & $7.32(2.75)$ & $7.65(2.76)$ & $6.74(2.67)$ & $7.74 * * *$ & $.72(.71, .74)$ & $.72(.71, .74)$ & NA \\
\hline Item 1 & $0-3$ & $1.93(.93)$ & NA & NA & NA & NA & NA & .67 \\
\hline Item 4 & $0-3$ & $1.80(.98)$ & NA & NA & NA & NA & NA & .72 \\
\hline Item 13 & $0-3$ & $1.95(.96)$ & NA & NA & NA & NA & NA & .71 \\
\hline Item 18 & $0-3$ & $1.64(1.01)$ & NA & NA & NA & NA & NA & .72 \\
\hline ASRQ factor 2 & $0-12$ & $2.25(2.08)$ & $2.16(2.12)$ & $2.40(2.01)$ & $-2.74 * *$ & $.76(.74, .77)$ & $.77(.75, .78)$ & NA \\
\hline Item 2 & $0-3$ & $.63(.76)$ & NA & NA & NA & NA & NA & .75 \\
\hline Item 6 & $0-3$ & $.49(.74)$ & NA & NA & NA & NA & NA & .78 \\
\hline Item 9 & $0-3$ & $.75(.75)$ & NA & NA & NA & NA & NA & .64 \\
\hline Item 12 & $0-3$ & $.39(.69)$ & NA & NA & NA & NA & NA & .64 \\
\hline ASRQ factor 3 & $0-24$ & $2.18(2.67)$ & $1.91(2.32)$ & $2.67(3.12)$ & $-6.11 * * *$ & $.87(.86, .88)$ & $.87(.87, .88)$ & NA \\
\hline Item 11 & $0-3$ & $.31(.64)$ & NA & NA & NA & NA & NA & .58 \\
\hline Item 17 & $0-3$ & $.22(.49)$ & NA & NA & NA & NA & NA & .64 \\
\hline Item 20 & $0-3$ & $.26(.55)$ & NA & NA & NA & NA & NA & .69 \\
\hline Item 23 & $0-3$ & $.17(.47)$ & NA & NA & NA & NA & NA & .61 \\
\hline Item 25 & $0-3$ & $.18(.48)$ & NA & NA & NA & NA & NA & .68 \\
\hline Item 31 & $0-3$ & $.19(.47)$ & NA & NA & NA & NA & NA & .61 \\
\hline Item 33 & $0-3$ & $.70(.78)$ & NA & NA & NA & NA & NA & .56 \\
\hline Item 35 & $0-3$ & $.17(.46)$ & NA & NA & NA & NA & NA & .56 \\
\hline ASRQ factor 4 & $0-24$ & $18.04(4.86)$ & $19.28(4.18)$ & $15.87(5.22)$ & $16.01 * * *$ & $.83(.82, .84)$ & $.84(.83, .85)$ & NA \\
\hline Item 7 (inverse) & $0-3$ & $2.74(.62)$ & NA & NA & NA & NA & NA & .42 \\
\hline Item 16 & $0-3$ & $1.74(1.19)$ & NA & NA & NA & NA & NA & .65 \\
\hline Item 19 & $0-3$ & 1.99 (1.09) & NA & NA & NA & NA & NA & .70 \\
\hline Item 22 & $0-3$ & $2.50(.99)$ & NA & NA & NA & NA & NA & .53 \\
\hline Item 24 & $0-3$ & $2.15(1.13)$ & NA & NA & NA & NA & NA & .67 \\
\hline Item 28 & $0-3$ & $2.26(1.02)$ & NA & NA & NA & NA & NA & .69 \\
\hline Item 29 & $0-3$ & $2.37(.95)$ & NA & NA & NA & NA & NA & .61 \\
\hline Item 30 & $0-3$ & $2.21(.96)$ & NA & NA & NA & NA & NA & .52 \\
\hline
\end{tabular}

I-F $r$, corrected item-factor correlation; $N A$, not applicable

${ }^{* *} p<0.01 ; * * * p<0.001$ 


\section{Convergent Validity of the ASRQ}

To determine convergent validity, we correlated the ASRQ factor scores with instruments used to assess a similar construct or related dimensions (Table 4). The results obtained reveal that the PaVa-SA total score correlates positively and significantly with factors 1 and 4 of the ASRQ (factor $1, r=.132 ; p=.034$; factor $4, r=.305 ; p<.001$ ), which evaluate assertive behavior, whereas it correlates negatively and significantly with factor 3 of the ASRQ ( $r$ $=-.218 ; p<.001$ ), which assesses over-assertive behavior. The correlation with factor 2 of the ASRQ, which measures sub-assertive behavior, was also negative, but not statistically significant $(r=-.018 ; p=.774)$.

In addition, some ASRQ factors show statistically significant correlations with other scales that evaluate constructs theoretically related to SA. Specifically, the Sexual Esteem subscale of the MSQ correlates positively and significantly with factors 1 and 3 of the ASRQ (factor $1, r=.290 ; p<.001$; factor $3, r=.148 ; p<.001$ ), which assess assertive and overly assertive behaviors, respectively. With factor 4 of the ASRQ, which evaluates the ability to respond assertively, the correlation was positive but not statistically significant $(r=.025 ; p=.428)$. In addition, it correlates negatively and significantly with factor 2 of the ASRQ $(r=-.340 ; p<.001)$, which measures sub-assertive behavior.

\section{Discussion}

As observed when analyzing the existing literature, assertive communication of sexual desires, thoughts, and feelings contributes to the development of healthy sexuality (Brassard et al., 2015), which has implications in different aspects of life (Attaky et al., 2020). With this in mind, this study aimed to develop, refine, and test the psychometric properties of the ASRQ, an instrument to assess SA in the Spanish context. This scale was developed to overcome some of the limitations that discourage the use of available assessment scales, such as their focus on the female population, the lack of assessment of some important assertive components (e.g., assertive communication under the influence of alcohol or other drugs), or the consideration of only affective and stable relationships. The ASRQ is a 24-item scale designed to be administered as a self-reported measure that is consistent with current social changes and new ways of relating sexually.

Furthermore, the ASRQ items reflect the idea that assertiveness is a continuum ranging from overly passive communication to the overly hostile expression of desires, thoughts, and opinions. Thus, the ASRQ shows a four-factor structure, provided by the EFA, which was verified and corrected through CFA, and so it can be stated that the final version of the 24-item ASRQ has good construct validity.

The first factor, "Assertive behavior as initiative," includes four items that reflect people's ability to actively make requests and initiate desired sexual practices assertively, taking into account the wishes and opinions of the other person. The content of this factor has been recognized as one of the most important ingredients of SA (Morokoff et al., 1997; Quina et al., 2000), and this aspect has been strongly associated with sexual experience. Contrary to the results obtained in our sample, it has traditionally been considered more socially appropriate for women to refuse sex than to initiate it (Grøntvedt et al., 2015). Our findings could be a reflection of the social empowerment of women pursued by today's society and the tendency toward a decrease in social gender stereotypes (Petersen \& Hyde, 2010). Moreover, as expected, the ability to initiate sexual activity and negotiate desirable sexual behavior seems to have a positive impact on sexual well-being and relational satisfaction for couples (Greene \& Faulkner, 2005).

The second factor, "Sub-assertive behavior," evaluates, through four items, the tendency to present passive behavior, which includes not being able to formulate requests based on one's preferences or respond appropriately when unwanted sexual practices are proposed, or show a lack of initiative and withdrawal for various reasons, such as shame. These aspects have been linked to negative consequences because they reduce the ability to negotiate during sexual practices. The literature has shown that some of these negative outcomes are related to sexual violence and the risk of sexually transmitted infections and unwanted pregnancies (Kelley et al., 2016; Kennedy \& Jenkins, 2011; Livingston et al., 2007; Morokoff et al., 2009; Williams et al., 2013). In the patriarchal dominant culture, women have historically
Table 4 Correlation indexes between the ASRQ factors and other measures

\begin{tabular}{lllll}
\hline & ASRQ factor 1 & ASRQ factor 2 & ASRQ factor 3 & ASRQ factor 4 \\
\hline PaVa-SA & $.132^{*}$ & -.018 & $-.218^{* * *}$ & $.305^{* * *}$ \\
$\begin{array}{l}\text { Sexual Esteem sub- } \\
\text { scale of MSQ }\end{array}$ & $.290^{* * *}$ & $-.340^{* * *}$ & $.148^{* * *}$ & .025 \\
\hline
\end{tabular}

$\mathrm{PaVa}-\mathrm{SA}$, parental values transmitted in relation to sexual assertiveness; $M S Q$, Multidimensional Sexuality Questionnaire

${ }^{*} p<.05 ; * * * p<.001$ 
been portrayed as taking a passive, submissive, and responsive role, rather than being active in the heterosexual context (Schwartz \& Rutter, 2000; Zhang \& Yip, 2018). Thus, they have tended to sacrifice their own sexual needs by being sexually complacent and preferring to please a partner rather than pursuing their own sexual enjoyment (Klein et al., 2019). As a result, it could be hypothesized that women would score higher than men on this subscale; however, the current social trend is changing, which implies a change in gender-role expectations as well. Evidence for this is found in our study.

The third factor, "Over-assertive behavior as initiative," groups eight items that reflect the tendency to make requests using more hostile communication where one's own sexual desires or preferences are imposed on the sexual partner, highlighting the pressure exerted to carry them out. This factor represents an important social issue in the context of sexual practices and has been found in several studies as the coercion and pressure to engage in unwanted sexual practices (Davis, 2019; Davis et al., 2014; Kuyper et al., 2013). For example, Shin et al., (2011) reported that $33.6 \%$ of university students had some unwanted sexual contact where one partner used psychological pressure or physical force to carry out desired sexual practices and would not accept the other's refusal. Some research has warned that such sexual contacts, which arise from coercion or pressure rather than will, have become all too common among young people, and initiatives must be taken to curb this tendency (FernándezFuertes et al., 2020; Kim et al., 2019). As in FernándezFuentes et al. (2020), our study reports higher scores on this factor in males than in females. Likewise, it is also noteworthy that those who present more hostile sexual communication seem to evaluate more positively their ability to relate sexually with another person. This could be explained by the tendency of people with a more directive communicative style to have their sexual desires satisfied more frequently, and to pair up with more passive people who comply with their sexual preferences without showing their dissatisfaction (Brak-Lamy, 2015; Jesser, 1978; Sanchez et al., 2012), which positively influences the increase in their sexual self-esteem.

The fourth and final factor, "Assertive behavior as a response," consists of eight items that evaluate people's ability to respond assertively to sexual requests, taking into account their own wishes and preferences and refusing unwanted practices without belittling or hurting the other person. In addition, it includes some items that assess the person's ability to negotiate the use of condoms and other barrier methods, and reject sexual practices that endanger their health. This content is also considered an essential component of SA in many studies (Morokoff et al., 1997; Loshek $\&$ Terrell, 2015) because refusal to engage in unwanted sexual practices is considered a central aspect of being sexually assertive. Although refusing unwanted sex is hindered by traditional feminine gender roles, Stulhofer et al., (2007) established that young women tend to report higher sexual refusal than men in the West, which is in line with the findings of our study. In addition, it should be pointed out that lower levels of assertive refusal have been associated with increased likelihood of completed rape (Söchting et al., 2004) and with blaming rape survivors in some scenarios (Rusinko et al., 2010).

Moreover, as Loshek and Terrell, (2015) pointed out, it should be noted that SA is probably an important construct for men as well, although most of the instruments published so far have not taken this population group into account. In this line, the ASRQ overcomes this methodological limitation because its factor structure was found to be equivalent in men and women. This fact is especially noteworthy today because, although traditionally more aggressive requests and coercion have been attributed to men (Krahé et al., 2014; 2015), it is necessary to evaluate the full construct of SA in the current sexual context where women seem to have gained some empowerment or made advances toward gender equality (Petersen \& Hyde, 2010). In addition, some problems related to rejection of unwanted sexual practices have also been identified in men (Santos-Iglesias et al., 2013).

Regarding the psychometric properties, all the items are adequate because item-factor co-relations with values greater than 0.30 are obtained (Nunnally \& Bernstein, 1995). All the subscales are composed of more than three items, with this being the minimum number of items to specify the latent factors (Raubenheimer, 2004). With regard to reliability, the four factors present adequate internal consistency, with values above 0.70 . These results, along with the values of the omega coefficients, indicate that the ASRQ is a reliable and valid measure for assessing SA.

In terms of evidence of convergent validity, our results show significant correlations in the expected directions between PaVa-SA, which assesses the respondent's perception of the values their parents transmitted to them about assertive communication with a partner, and ASRQ factors that assess assertive behavior as initiative and as response and the tendency to make hostile sexual requests (Deiter, 1994; Quina et al., 2000). Although it is evident that the communication skills of the respondent with his or her sexual partner may discern from the values regarding assertive communication transmitted by parents, it can be understood that the two instruments offer complementary information and assess a directly linked construct (EstruchGarcía \& Gil-Llario, 2020), since parents occupy a fundamental role in the sexual behavior of their children as the main agents of socialization and transmitters of skills and values (Bárcena et al., 2013; Manago et al., 2015), prevailing, thus, the reproduction of interaction patterns learned in the family of origin (López Alvarado et al., 2019; Pai 
et al., 2011). Likewise, significant correlations have been found between the Sexual Esteem subscale of the MSQ and assertive behavior as initiative and the tendency to carry out hostile or passive requests/responses, all of them in the expected directions as well (Ménard \& Offman, 2009). Obviously, these instruments do not assess the same construct, but, given that SA and sexual self-esteem are predictor variables (Brassard et al., 2015), their correlation allows us to confirm that our instrument assesses the desired construct. This procedure for analyzing convergent validity has been used in other studies that have created questionnaires to assess SA (Torres-Obregon et al., 2017).

The validation of the Assertiveness in Sexual Relations Questionnaire yielded favorable results, showing that it is a reliable, valid, and effective tool to assess SA that can be applied to men and women without changing its factor structure. However, it is important to note that this study also has some limitations, and it does not provide data about testretest stability. Future research should address the assessment of this construct at two points in time in order to measure test-retest reliability. It is also important to bear in mind that the validation of this instrument has only been carried out in a Spanish-speaking context, and future studies should find out whether the same factorial structure would be replicated in an English-speaking general population. Finally, it would be interesting to adapt and validate this instrument in a clinical population (e.g., people diagnosed with schizophrenia, depression) in order to better tailor interventions and test whether this scale is able to monitor changes in SA after the implementation of psychological interventions.

\section{Conclusions}

The availability of an instrument to assess sexual assertiveness, whose psychometric properties have been satisfactorily tested, has important social implications. Lack of sexual assertiveness often underlies many sexual satisfaction problems, given the anxiety of unwanted sexual interactions, and is directly linked to the risk of sexual victimization. Also, engaging in unwanted sex increases the risk of engaging in risky sexual behavior (unprotected sex, STIs, unwanted pregnancies, etc.).

In this sense, the present study contributes to the work of many sexual health professionals, who would benefit from an instrument such as the one proposed that allows them to determine the pattern of interaction that patients establish with their sexual partners, especially when they come for consultation due to sexual problems. However, this instrument could not only be useful in interventions with victims of sexual abuse/assault, but also allows for the identification of disruptive sexual interaction patterns of sexual offenders, which could contribute to the effective social reintegration of this group. Finally, this paper contributes to highlighting the importance of working on young people's ability to establish desirable and healthy sexual encounters, including sexual assertiveness as an aspect to work on in sexuality education programs.

Author Contribution Maria Dolores Gil-Lario and Rafael BallesterArnal were involved in the study design and supervision, and in the design of questionnaire. Beatriz Gil-Juliá was in charge of updating the bibliography. Olga Fernández-García and Verónica Estruch-García participated in recruiting participants and collecting data. Maria Dolores Gil-Llario and Olga Fernández-García carried out the analysis/interpretation of data. All authors contributed to the writing of the paper and approved the final manuscript.

Funding Open Access funding provided thanks to the CRUE-CSIC agreement with Springer Nature.

Availability of Data and Material The reader can consult any doubt about the data and material by contacting the corresponding author.

Code Availability Not applicable.

\section{Declarations}

Ethics Approval All procedures performed in studies involving human participants were in accordance with the ethical standards of the institutional and/or national research committee and with the 1964 Helsinki Declaration and its later amendments or comparable ethical standards. The study was approved by the Human Research Ethics Committee of the Experimental Research Ethics Committee of the Universitat de València.

Consent to Participate Volunteer participants in the research were informed of the study aim and completed an informed consent forms before proceeding with the questionnaire.

Conflict of Interest The authors declare no competing interests.

Open Access This article is licensed under a Creative Commons Attribution 4.0 International License, which permits use, sharing, adaptation, distribution and reproduction in any medium or format, as long as you give appropriate credit to the original author(s) and the source, provide a link to the Creative Commons licence, and indicate if changes were made. The images or other third party material in this article are included in the article's Creative Commons licence, unless indicated otherwise in a credit line to the material. If material is not included in the article's Creative Commons licence and your intended use is not permitted by statutory regulation or exceeds the permitted use, you will need to obtain permission directly from the copyright holder. To view a copy of this licence, visit http://creativecommons.org/licenses/by/4.0/.

\section{References}

Alberti, R. E., \& Emmons, M. L. (1978). Your perfect right: A guide to assertive behavior. Impact Press. 
Attaky, A., Kok, G., \& Dewitte, M. (2020). Attachment insecurity and sexual and relational experiences in Saudi Arabian women: The role of perceived partner responsiveness and sexual assertiveness. The journal of sexual medicine, 17(7), 1383-1394. https://doi.org/ 10.1016/j.jsxm.2020.02.029

Bagozzi, R. P., \& Yi, Y. (2011). Specification, evaluation, and interpretation of structural equation models. Journal of the Academy of Marketing Science, 40(1), 8-34. https://doi.org/10.1007/ s11747-011-0278-x

Ballester-Arnal, R., \& Gil-Juliá, B. (2012). Assertiveness training. In R. Neimeyer (Ed.), Techniques of grief therapy: Creative practices for counseling the bereaved (pp.117-119). Routledge. ISBN: 978-0-415-80725-8.

Bárcena, S., Robles, S., \& Díaz-Loving, R. (2013). El papel de los padres en la salud sexual de sus hijos. Acta de investigación psicológica, 3(1), 956-968. https://doi.org/10.1016/S20074719(13)70945-1

Brak-Lamy, G. (2015). Heterosexual seduction in the urban night context: Behaviors and meanings. The Journal of Sex Research, 52(6), 690-699. https://doi.org/10.1080/00224499.2013.856835

Brassard, A., Dupuy, E., Bergeron, S., \& Shaver, P. R. (2015). Attachment insecurities and women's sexual function and satisfaction: The mediating roles of sexual self-esteem, sexual anxiety, and sexual assertiveness. Journal Sexuality Research, 52(1), 110-119. https://doi.org/10.1080/00224499.2013.838744

Carrobles, J. A., Guadix, M. G., \& Almendros, C. (2011). Funcionamiento sexual, satisfacción sexual y bienestar psicológico y subjetivo en una muestra de mujeres españolas. Anales de Psicología, 27(1), 27-34. http://www.redalyc.org/articulo.oa? id=16717018004

Davis, K. C. (2019). “Stealthing": Factors associated with young men's nonconsensual condom removal. Health psychology, 38(11), 997100. https://doi.org/10.1037/hea0000779

Davis, K. C., Stappenbeck, C. A., Norris, J., George, W. H., JacquesTiura, A. J., Schraufnagel, T. J., \& Kajumulo, K. F. (2014). Young men's condom use resistance tactics: A latent profile analysis. Journal of Sex Research, 51(4), 454-465. https://doi.org/10.1080/ 00224499.2013.776660

Deiter, P. J. (1994). Sexual assertiveness training for college women: An intervention study. Dissertation, University of Rhode Island.

DiStefano, C., \& Morgan, G. B. (2014). A comparison of diagonal weighted least squares robust estimation techniques for ordinal data. Structural Equation Modeling: A Multidisciplinary Journal, 21(3), 425-438. https://doi.org/10.1080/10705511.2014.915373

Erchull, M., \& Liss, M. (2014). The object of one's desire: How perceived sexual empowerment through objectification is related to sexual outcomes. Sexuality \& Culture, 18(4), 773-788. https://doi. org/10.1007/s12119-013-9216-Z

Estruch-García, V., \& Gil-Llario, M. D. (2020). Análisis de la asertividad sexual en jóvenes y adultos: relación con el sexismo y la autoestima sexual [Master's Thesis]. University of Valencia.

Fernández-Fuertes, A. A., Fernández-Rouco, N., Lázaro-Visa, S., \& Gómez-Pérez, E. (2020). Myths about sexual aggression, sexual assertiveness and sexual violence in adolescent romantic relationships. International journal of environmental research and public health, 17(23), 8744. https://doi.org/10.3390/ijerph17238744

Fernández-Fuertes, A. A., Orgaz, B., \& Fuertes, A. (2011). Características del comportamiento agresivo en las parejas de los adolescentes españoles. Psicologia Conductual, 19(3), 501-522.

Ferrando, P. J., \& Lorenzo-Seva, U. (2017). Program FACTOR at 10: Origins, development and future directions. Psicothema, 29(2), 236-240. https://doi.org/10.7334/psicothema2016.304

Finney, S. J., \& DiStefano, C. (2013). Nonnormal and categorical data in structural equation modeling. In G. R. Hancock \& R. O. Mueller (Eds.), Structural equation modeling: A second course (2nd ed., pp. 439-492). Information Age Publishing.
Garrido, L. E., Abad, F. J., \& Ponsoda, V. (2013). A new look at Horn's parallel analysis with ordinal variables. Psychological Methods, 18(4), 454-474. https://doi.org/10.1037/a0030005

Gil-Llario, M. D., Morell-Mengual, V., Ruiz-Palomino, E., \& BallesterArnal, R. (2019). Factorial structure and psychometric properties of a brief scale of the condom use self-efficacy for Spanish-speaking people. Health education \& behavior: the official publication of the Society for Public Health Education, 46(2), 295-303. https://doi. org/10.1177/1090198118806964

Giordano, F. G., \& Rush, C. L. (2010). Self-esteem and sexuality: An exploration of differentiation and attachment. In M. H. Guindon (Ed.), Self-esteem across the lifespan: Issues and interventions (pp. 205-218). Routledge.

Greene, K., \& Faulkner, S. L. (2005). Gender, belief in the sexual double standard, and sexual talk in heterosexual dating relationships. Sex Roles, 53, 239-251. https://doi.org/10.1007/ s11199-005-5682-6

Grøntvedt, T. V., Kennair, L. E. O., \& Mehmetoglu, M. (2015). Factors predicting the probability of initiating sexual intercourse by context and sex. Scandinavian Journal of Psychology, 56(5), 516-526. https://doi.org/10.1111/sjop. 12215

Hooper, D., Coughlan, J., \& Mullen, M. R. (2008). Structural equation modeling: Guidelines for determining model fit. Electronic Journal on Business Research Methods, 6(1), 53-60.

Hunsley, J., \& Mash, E. J. (2008). A guide to assessments that work. Oxford University Press.

Hurlbert, D. F. (1991). The role of assertiveness in female sexuality: A comparative study between sexually assertive and sexually nonassertive women. Journal of Sex and Marital Therapy, 17(3), 183-190. https://doi.org/10.1080/00926239108404342

Impett, E. A., \& Peplau, L. A. (2003). Sexual compliance: Gender, motivational, and relationship perspectives. The Journal of Sex Research, 40(1), 87-100. https://doi.org/10.1080/0022449030 9552169

Jesser, C. J. (1978). Male responses to direct verbal sexual initiatives of females. Journal of Sex Research, 14(2), 118-128. https://doi. org/10.1080/00224497809551000

Kelley, E. L., Orchowski, L. M., \& Gidycz, C. A. (2016). Sexual victimization among college women: Role of sexual assertiveness and resistance variables. Psychology of Violence, 6(2), 243-252. https://doi.org/10.1037/a0039407

Kelly, J. A. (2000). Social-skills training. A practical guide for intervention. Springer Publishing Co.

Kennedy, B. R., \& Jenkins, C. C. (2011). Promoting African American women and sexual assertiveness in reducing HIV/AIDS: an analytical review of the research literature. Journal of Cultural Diversity, $18(4), 142-149$.

Kim, Y., Lee, E., \& Lee, H. (2019). Sexual double standard, dating violence recognition, and sexual assertiveness among university students in South Korea. Asian Nursing Research (Korean Society of Nursing Science), 13(1), 47-52. https://doi.org/10.1016/j.anr. 2019.01.003

Klein, V., Imhoff, R., Reininger, K. M., \& Briken, P. (2019). Perceptions of sexual script deviation in women and men. Archives of Sexual Behavior, 48(2), 631-644. https://doi.org/10.1007/ s10508-018-1280-x

Koolaee, A. K., Asadi, E., Mansoor, L., Mosalanejad, L., \& Fath Abadi, A. (2014). A holistic approach to psychological sexual problems in women with diabetic husbands. Iranian Journal of Reproductive Medicine, 12(3), 175-182.

Krahé, B., \& Berger, A. (2017). Longitudinal pathways of sexual victimization, sexual self-esteem, and depression in women and men. Psychological Trauma: Theory, Research, Practice, and Policy, 9(2), 147-155. https://doi.org/10.1037/tra0000198

Krahé, B., Berger, A., Vanwesenbeeck, I., Bianchi, G., Chliaoutakis, J., Fernández-Fuertes, A. A., \& Zygadło, A. (2015). Prevalence and 
correlates of young people's sexual aggression perpetration and victimisation in 10 European countries: A multi-level analysis. Culture, health \& sexuality, 17(6), 682-699. https://doi.org/10. 1080/13691058.2014.989265

Krahé, B., Tomaszewska, P., Kuyper, L., \& Vanwesenbeeck, I. (2014). Prevalence of sexual aggression among young people in Europe: A review of the evidence from 27 EU countries. Aggression and Violent Behavior, 19(5), 545-558. https://doi.org/10.1016/j.avb. 2014.07.005

Kuyper, L., de Wit, J., Smolenski, D., Adam, P., Woertman, L., \& van Berlo, W. (2013). Gender differences in patterns of experienced sexual coercion and associated vulnerability factors among young people in the Netherlands. Journal of interpersonal violence, 28(16), 3149-3170. https://doi.org/10.1177/0886260513488689

Lammers, J., \& Stoker, J. I. (2019). Power affects sexual assertiveness and sexual esteem equally in women and men. Archives of Sexual Behavior, 48(2), 645-652. https://doi.org/10.1007/ s10508-018-1285-5

Livingston, J. A., Testa, M., \& VanZile-Tamsen, C. (2007). The reciprocal relationship between sexual victimization and sexual assertiveness. Violence Against Women, 13(3), 298-313. https://doi. org/10.1177/1077801206297339

Long, J. S. (1983). Confirmatory factor analysis. Sage.

López Alvarado, S. L., Cevallos Neira, A. C., \& Jerves, E. (2019). La asertividad sexual en adultos de la ciudad de Cuenca: un estudio exploratorio. RELIES: Revista del Laboratorio Iberoamericano para el Estudio Sociohistórico de las Sexualidades, 1, 3-25.

Lorenzo-Seva, U., \& Ferrando, P. J. (2013). FACTOR 9.2: A comprehensive program for fitting exploratory and semiconfirmatory factor analysis and IRT models. Applied Psychological Measurement, 37(6), 497-498. https://doi.org/10.1177/0146621613487794

Loshek, E., \& Terrell, H. K. (2015). The development of the Sexual Assertiveness Questionnaire (SAQ): A comprehensive measure of sexual assertiveness for women. The Journal of Sex Research, 52(9), 1017-1027. https://doi.org/10.1080/00224 499.2014.944970

Manago, A. M., Ward, L. M., \& Aldana, A. (2015). The sexual experience of Latino young adults in college and their perceptions of values about sex communicated by their parents and friends. Emerging adulthood, 3(1), 14-23. https://doi.org/10.1177/21676 96814536165

Markland, D. (2007). The golden rule is that there are no golden rules: A commentary on Paul Barrett's recommendations for reporting model fit in structural equation modelling. Personality and Individual Differences, 42(5), 851-858. https://doi.org/10.1016/j.paid. 2006.09.023

Ménard, A. D., \& Offman, A. (2009). The interrelationships between sexual self-esteem, sexual assertiveness and sexual satisfaction. Canadian Journal of Human Sexuality, 18(1-2), 35-45.

Mokkink, L. B., Terwee, C. B., Patrick, D. L., Alonso, J., Stratford, P. W., Knol, D. L., Bouter, L. M., \& De Vet, H. C. W. (2010). The COSMIN checklist for assessing the methodological quality of studies on measurement properties of health status measurement instruments: An international Delphi study. Quality of Life Research, 19(4), 539-549. https://doi.org/10.1007/ s11136-010-9606-8

Morokoff, P. J., Quina, K., Harlow, L. L., Whitmire, L., Grimley, D. M., Gibson, P. R., \& Burkholder, G. J. (1997). Sexual Assertiveness Scale (SAS) for women: Development and validation. Journal of personality and social psychology, 73(4), 790-804. https://doi. org/10.1037/0022-3514.73.4.790

Morokoff, P. J., Redding, C. A., Harlow, L. L., Cho, S., Rossi, J. S., Meier, K. S., \& Brown-Peterside, B. (2009). Associations of sexual victimization, depression, and sexual assertiveness with unprotected sex: A test of the multi-faceted model of HIV risk across gender. Journal of Applied Biobehavioral Research, 14(1), 30-54. https://doi.org/10.1111/j.1751-9861.2009.00039.x

Nunnally, J. C., \& Bernstein, I. J. (1995). Teoría psicométrica. McGrawHill.

Pai, H. C., Lee, S., \& Yen, W. J. (2011). The effect of sexual selfconcept on sexual health behavioural intentions: A test of moderating mechanisms in early adolescent girls. Journal of advanced nursing, 68(1), 47-55.

Paredes Robalino, M V., Calderón León, C. F. \& Toapanta Yanzaguano, M. A. (2020). Autoerotismo y la sexualidad en los estudiantes de la carrera de psicología educativa, orientación vocacional y familiar de la facultad de ciencias de la educación humanas y tecnologías de la Unach período abril-agosto 2019 [Thesis], Universidad Nacional de Chimborazo, Chimborazo. Digital Repository UNACH. http://dspace.unach.edu.ec/handle/51000/6441

Petersen, J. L., \& Hyde, J. S. (2010). A meta-analytic review of research on gender differences in sexuality, 1993-2007. Psychological Bulletin, 136(1), 21-38. https://doi.org/10.1037/a0017504

Quina, K., Harlow, L. L., Morokoff, P. J., \& Burkholder, G. (2000). Sexual communication in relationships: When words speak louder than actions. Sex Roles, 42, 523-549. https://doi.org/10.1023/A: 1007043205155

Raubenheimer, J. (2004). An item selection procedure to maximise scale reliability and validity. Journal of Industrial Psychology, 30(4), 59-64. https://doi.org/10.4102/sajip.v30i4.168

Rusinko, H. M., Bradley, A. R., \& Miller, J. (2010). Assertiveness and attributions of blame toward victims of sexual assault. J. Aggress. Maltreat. Trauma., 19(4), 357-371. https://doi.org/10.1080/10926 771003788961

Sanchez, D. T., Phelan, J. E., Moss-Racusin, C. A., \& Good, J. J. (2012). The gender role motivation model of women's sexually submissive behavior and satisfaction in heterosexual couples. Personality and Social Psychology Bulletin, 38(4), 528-39. https:// doi.org/10.1177/0146167211430088

Santos-Iglesias, P., Sierra, J. C., \& Vallejo-Medina, P. (2013). Predictors of sexual assertiveness: The role of sexual desire, arousal, attitudes, and partner abuse. Archives of Sexual Behavior, 42(6), 1043-1052. https://doi.org/10.1007/s10508-012-9998-3

Santos-Iglesias, P., Vallejo-Medina, P., \& Sierra, J. C. (2014). Equivalence and standard scores of the Hurlbert Index of Sexual Assertiveness across Spanish men and women. Anales de Psicología, 30(1), 233-238. https://doi.org/10.6018/analesps.30.1.143321

Schwartz, P., \& Rutter, V. (2000). The gender of sexuality (2nd ed.). Pine Forge Press.

Shin, K. R., Park, H., \& Cha, C. (2011). Sex education during the school-aged years influences sexual attitudes and sexual health in college: a comparative study from Korea. Nursing Health Science., 13(3), 328-334. https://doi.org/10.1111/j.1442-2018. 2011.00622.x

Snell, W. E., Fisher, T. D., \& Walters, A. S. (1993). The Multidimensional Sexuality Questionnaire: An objective self-report measure of psychological tendencies associated with human sexuality. Annals of Sex Research, 6, 27-55. https://doi.org/10.1177/10790 6329300600102

Söchting, I., Fairbrother, N., \& Koch, W. J. (2004). Sexual assault of women: prevention efforts and risk factors. Violence Against Women, 10(1), 73-93. https://doi.org/10.1177/1077801203255680

Soriano-Ayala, E. \& García-Serrán, H. (2019). Amigos con beneficios vs. sexo casual: definiendo sus comportamientos sexuales, amor, celos y creencias románticas. Universitas Psychologica, 18(2), 1-13. https://doi.org/10.11144/Javeriana.upsy18-2.absc

Speed, B. C., Goldstein, B. L., \& Goldfried, M. R. (2018). Assertiveness training: A forgotten evidence-based treatment. Clinical Psychology Science and Practice, 25(1), 1-20. https://doi.org/10. $1111 /$ cpsp. 12216 
Stappenbeck, C. A., Gulati, N. K., \& Davis, K. C. (2019). A prospective examination of men's condom use resistance: Event-level associations with sexual aggression, alcohol consumption, and trait anger. The Journal of Sex Research, 56(8), 947-956. https:// doi.org/10.1080/00224499.2019.1620162

Stulhofer, A., Graham, C., Bozicevic, I., Kufrin, K., \& Ajdukovic, D. (2007). An assessment of HIV/STI vulnerability and related sexual risk-taking in a nationally representative sample of young Croatian adults. Archives of Sexual Behavior, 38(2), 209-225. https://doi.org/10.1007/s10508-007-9234-8

Teitelman, A. M., Bohinski, J. M., \& Boente, A. (2009). The social context of sexual health and sexual risk for urban adolescent girls in the United States. Issues Mental Health Nursing, 30, 460-469. https://doi.org/10.1080/01612840802641735

Timmerman, M. E., \& Lorenzo-Seva, U. (2011). Dimensionality assessment of ordered polytomous items with parallel analysis. Psychological Methods, 16(2), 209-220. https://doi.org/10.1037/a0023353

Torres-Obregon, R., Onofre-Rodríguez, D. J., Sierra, J. C., BenavidesTorres, R. A., \& Garza-Elizondo, M. E. (2017). Validación de la Sexual Assertiveness Scale en mujeres mexicanas. Suma psicológica, 24(1), 34-41. https://doi.org/10.1016/j.sumpsi.2017. 01.001

Vannier, S. A., \& O'Sullivan, L. F. (2011). Communicating interest in sex: Verbal and nonverbal initiation of sexual activity in young adults' romantic dating relationships. Archives of Sexual Behavior, 40(5), 961-969. https://doi.org/10.1007/s10508-010-9663-7
Wiederman, M. W. (2015). Sexual script theory: Past, present, and future. En J. DeLamater y R. F. Plante (Ed.), New York: Handbook of the sociology of sexualities (pp. 7-22). Springer.

Williams, C. M., Clear, E. R., \& Coker, A. L. (2013). Sexual coercion and sexual violence at first intercourse associated with sexually transmitted infections. Sexually transmitted diseases, 40(10), 771-776. https://doi.org/10.1097/OLQ.0000000000000011

Wincentak, K., Connolly, J., \& Card, N. (2017). Teen dating violence: A meta-analytic review of prevalence rates. Psychology Violence, 7(2), 224-241. https://doi.org/10.1037/a0040194

Zamboni, B. D., Crawford, I., \& Williams, P. G. (2000). Examining communication and assertiveness as predictors of condom use: Implications for HIV prevention. AIDS Education and Prevention, 12(6), 492-504. https://doi.org/10.1037/a0040194

Zhang, H., \& Yip, P. S. F. (2018). Perceived and actual behavior in female sexual assertiveness: A within-couple analysis in Hong Kong. Journal of Sex \& Marital Therapy, 44(1), 87-95. https:// doi.org/10.1080/0092623X.2017.1321597

Publisher's Note Springer Nature remains neutral with regard to jurisdictional claims in published maps and institutional affiliations. 